\title{
Sistem Pendukung Keputusan Seleksi Calon Siswa-Siswi Baru Menggunakan Metode Weighted Product (WP) (Studi Kasus : MTs Al Husna )
}

\author{
Syahriani Syam \\ Jurusan Teknik Informatika, Fakultas Teknik, Universitas Islam Syekh Yusuf, Jl. Mulana Yusuf No.10 Tangerang \\ Banten 15118, Indonesia \\ $\underline{\text { ssyam@unis.ac.id }}$
}

\begin{abstract}
Abstrak. Sistem pendukung keputusan adalah salah satu sistem untuk menunjang keputusan dalam suatu organisasi baik dilingkungan pendidikan, kantor, maupun pemerintahan. Masalah administrasi yang masih manual mengakibatkan kurang efisien terhadap kegiatan seleksi calon siswa-siswi baru di MTs Al Husna .Metode Weighted Product adalah salah satu metode untuk melakukan pengambilan keputusan dengan sistem multi kriteria, dimana kriteria tersebut telah ditentukan oleh pihak sekolah. Dalam penelitian ini digunakan indikator kriteria yaitu nilai ujian nasional, nilai semester akhir, baca tulis al-qur'an, wawancara, tes tertulis dan penilaian terhadap prestasi non akademik. Dengan pemodelan fungsionalnya menggunakan use case diagram. Penelitian ini menghasilkan suatu aplikasi pendukung keputusan terhadap pemilihan calon siswa siswi baru.
\end{abstract}

Kata kunci: sistem pendukung keputusan, Weighted Product, mts al husna,

Abstract. Decision support system is one of the systems to support decisions in an organization both in the education, office and government environments. Administrative problems are still manual resulting in less efficient selection of prospective new students in MTs Al Husna. Weighted Product method is one method for making decisions with a multi-criteria system, where the criteria have been determined by the school. In this study the criteria used are national exam scores, final semester scores, al-quran writing, interviews, written tests and assessments of non-academic achievements. With functional modeling using use case diagrams. This research resulted in a decision support application to the selection of prospective new students.

Keywords: decision support system, Weighted Product, mts al husna

\section{Pendahuluan}

Kemajuan teknologi sangat berpengaruh terhadap perkembangan sekolah yang ada. Dalam era globalisasi, sekolah tidak bisa dijalankan dengan mengandalkan cara konvensional. Harus dibuat suatu strategi baru agar sekolah tersebut mampu menciptakan generasi yang lebih kreatif, cerdas dan berkualitas.

Masalah yang dirasakan selama ini pada proses seleksi penerimaan siswa baru adalah panitia seleksi belum memiliki sebuah sistem penilaian yang bisa digunakan secara transparan dan professional. Sehingga menyebabkan proses penyeleksian siswa yang akan diterima menjadi subjektif sehingga berdampak pada hasil penetapan siapa yang akan diluluskan pasca proses penyeleksian yang dilakukan oleh panitia seleksi dan pimpinan sekolah.

Permasalahan di atas dapat diperbaiki dengan membangun sebuah Sistem Pendukung Keputusan (SPK) dengan menerapkan metode Weighted Product (WP). Penerapan metode digunakan untuk membantu menyelesaikan masalah seleksi calon siswa-siswi baru, Sehingga diharapkan proses seleksi calon siswa-siswi akan lebih tepat, dan hasilnya bisa digunakan sebagai acuan dalam pengambilan keputusan secara tepat. Metode ini adalah sebuah kerangka untuk mengambil keputusan dengan efektif atas persoalan yang kompleks dengan menyederhanakan dan mempercepat proses pengambilan keputusan dengan memecahkan persoalan tersebut kedalam bagian-bagiannya.

\section{Rumusan Masalah}

Setelah melihat latar belakang masalah yang telah diuraikan di atas maka timbul rumusan masalah yaitu: "Bagaimana merancang sistem pendukung keputusan untuk menseleksi calon siswa-siswi baru dengan menggunakan metode Weighted Product (WP)?"

\section{Batasan Masalah}

Metode yang akan digunakan dalam sistem pendukung keputusan pada masalah ini adalah Weighted Product (WP), yang merupakan suatu pengambilan keputusan untuk menentukan alternatif terbaik berdasarkan beberapa kriteria tertentu. Implementasi dilakukan pada pengambilan keputusan 
dari beberapa aspek yang dinilai dari calon siswasiswi tersebut dengan kriteria yang digunakan adalah nilai semester akhir, nilai ujian nasional, test baca tulis Al-qur'an, test tertulis, wawancara, dan kriteria yang lainnya yang akan ditentukan setelah penelitian.

\section{Metode Weighted Product}

Metode Weighted Product (WP) merupakan metode pengambilan keputusan dengan cara perkalian untuk menghubungkan rating atribut, dimana rating setiap atribut harus dipangkatkan dulu dengan bobot atribut yang bersangkutan. Proses ini sama dengan proses normalisasi. Preferensi untuk atribut Si diberikan sebagai berikut (Kusumadewi, 2006):

$$
S i=\prod_{j=1}^{n} x_{i j} \quad W j
$$

dengan $\mathrm{i}=1,2, \ldots, \mathrm{n}$

dimana " $\sum$ " wj $=1$. $\mathrm{Wj}$ adalah pangkat bernilai positif untuk atribut keuntungan, dan bernilai negatif untuk atribut biaya.

Preperensi relatif dari setiap alternatif, diberikan sebagai :

$$
\mathrm{Vi}=\frac{\prod_{j=1}^{n} x_{i j}{ }^{w j}}{\prod_{j=1}^{n}\left(x_{j}^{*}\right)^{w j}}
$$

Dimana :

$$
\text { dengan } \mathrm{i}=1,2, \ldots . \mathrm{n}
$$

$\Pi=$ Produk

$\mathrm{V}=$ Preferensi alternatif di analogikan sebagai vektor $\mathrm{V}$

$\mathrm{X}=$ Nilai kriteria

$\mathrm{W}=$ Bobot kriteria/subkriteria

$\mathrm{i}=$ Alternatif

$\mathrm{j}=$ Kriteria

$\mathrm{n}=$ Banyaknya kriteria

*= Banyaknya kriteria yang telah dinilai pada vektor $\mathrm{S}$

Rating kecocokan setiap alternatif pada setiap kriteria, dinilai dengan 1 sampai 5 yaitu :

$1=$ sangat buruk

$2=$ buruk

3 = cukup

4 = baik

5 = sangat baik

Rating kepentingan setiap kriteria dinilai dengan 1 sampai 5, yaitu :

1 = sangat rendah

$2=$ rendah

3 = cukup

$4=$ tinggi

5 = sangat tinggi,

II. Bahan dan Metode
Dalam pemilihan calon siswa terdapat beberapa kriteria yang digunakan yaitu :

1. Nilai Semester Akhir

2. Nilai Ujian Nasional

3. Tes Baca Tulis Al-Qur'an

4. Tes Tertulis

5. Wawancara

6. Prestasi non akademik

Pembobotan metode Weighted Product dihitung berdasarkan tingkat kepentingan.

Tingkat kepentingan metode Weighted Product, yaitu menggunakan skala ordinalitas:

1. Sangat penting

2. Penting

3. Cukup penting

4. Kurang penting

5. Tidak penting

\section{Hasil dan Pembahasan}

Menentukan kelulusan pada saat seleksi adalah calon siswa yang memiliki nilai tertinggi pada saat seleksi.Dimana nilai tertingi terhadap calon siswa tersebut didapat dari kriteria kirteria yang telah ditentukan sebelumnya oleh kepala madrasah. kriteria-kriteria yang telah ditentukan adalah sebagai

\begin{tabular}{|c|c|c|}
\hline No. & Kode Kriteria & Nama Kriteria \\
\hline 1 & $\mathrm{C} 1$ & Nilai Semester Akhir \\
\hline 2 & $\mathrm{C} 2$ & Nilai Ujian Nasional \\
\hline 3 & $\mathrm{C} 3$ & $\begin{array}{l}\text { Test Baca Tulis Al- } \\
\text { Qur'an }\end{array}$ \\
\hline 4 & $\mathrm{C} 4$ & Test Tertulis \\
\hline 5 & $\mathrm{C} 5$ & Wawancara \\
\hline 6 & C6 & $\begin{array}{l}\text { Prestasi } \\
\text { Akademik }\end{array}$ \\
\hline
\end{tabular}
berikut.

Tabel 1. Kriteria-kriteria yang Ditentukan

Pemberian nilai kepentingan pada kriteria pada saat wawancara, kepala madrasah memberikan nilai kepentingan pada kriteria-kriteria tersebut sebagai berikut :

Tabel 2. Nilai Kepentingan pada Kriteria

\begin{tabular}{cclc}
\hline No. & $\begin{array}{c}\text { Kode } \\
\text { Kriteria }\end{array}$ & \multicolumn{1}{c}{$\begin{array}{c}\text { Nama } \\
\text { Kriteria }\end{array}$} & $\begin{array}{c}\text { Nilai } \\
\text { Kepentingan }\end{array}$ \\
\hline 1 & C1 & $\begin{array}{l}\text { Nilai } \\
\text { Semester } \\
\text { Akhir }\end{array}$ & 2 \\
\hline 2 & C2 & $\begin{array}{l}\text { Nilai Ujian } \\
\text { Nasional }\end{array}$ & 2 \\
\hline 3 & C3 & $\begin{array}{l}\text { Test Baca } \\
\text { Tulis Al- } \\
\text { Qur'an }\end{array}$ & 1 \\
\hline 4 & C4 & Test Tertulis & 2 \\
\hline 5 & C5 & Wawancara & 3 \\
\hline 6 & C6 & $\begin{array}{l}\text { Prestasi Non } \\
\text { Akademik }\end{array}$ & 3 \\
\hline
\end{tabular}


Menghitung nilai perbaikan bobot $(\mathrm{Wj})$ berdasarkan nilai prioritas bobot setiap kriteria yang sudah ditentukan

$$
w j=\frac{w j}{\sum w j}
$$

Maka untuk setiap kriteria didapatkan bobot sebagai berikut:

$$
\begin{aligned}
& \mathrm{C} 1=\frac{2}{2+2+1+2+3+3}=\frac{2}{13}=0,1538 \\
& \mathrm{C} 2=\frac{2}{2+2+1+2+3+3}=\frac{2}{13}=0,1538 \\
& \mathrm{C} 3=\frac{1}{2+2+1+2+3+3}=\frac{1}{13}=0,0769 \\
& \mathrm{C} 4=\frac{2}{2+2+1+2+3+3}=\frac{2}{13}=0,1538 \\
& \mathrm{C} 5=\frac{3}{2+2+1+2+3+3}=\frac{3}{13}=0,2307 \\
& \mathrm{C} 6=\frac{3}{2+2+1+2+3+3}=\frac{3}{13}=0,2307
\end{aligned}
$$

\begin{tabular}{|c|c|c|c|c|c|c|c|}
\hline \multirow[b]{2}{*}{ Ni } & \multirow{2}{*}{$\begin{array}{l}\text { Alternati } \\
\mathbf{f}\end{array}$} & \multicolumn{6}{|c|}{ Kriteria } \\
\hline & & $\begin{array}{l}\mathrm{C} \\
1\end{array}$ & $\begin{array}{l}\mathrm{C} \\
2\end{array}$ & $\mathrm{C3}$ & $\begin{array}{l}\mathrm{C} \\
4\end{array}$ & $\begin{array}{l}\text { C } \\
5\end{array}$ & $\begin{array}{l}C \\
6\end{array}$ \\
\hline 1 & $\begin{array}{l}\text { Srie } \\
\text { Fatika } \\
\text { Setyani }\end{array}$ & 89 & 90 & $\begin{array}{c}23 \\
5\end{array}$ & 78 & 77 & 4 \\
\hline 2 & $\begin{array}{l}\text { Fatwa } \\
\text { Maulida S }\end{array}$ & 78 & 77 & $\begin{array}{c}21 \\
0\end{array}$ & 89 & 90 & 3 \\
\hline 3 & $\begin{array}{l}\text { Fikram } \\
\text { Fadillah }\end{array}$ & 78 & 66 & $\begin{array}{c}24 \\
0\end{array}$ & 89 & 88 & 1 \\
\hline 4 & $\begin{array}{l}\text { Meita } \\
\text { Rosiyanti }\end{array}$ & 78 & 90 & $\begin{array}{c}23 \\
5\end{array}$ & 78 & 78 & 2 \\
\hline 5 & $\begin{array}{l}\text { Nida } \\
\text { Luthfiyati } \\
\text { S }\end{array}$ & 76 & 77 & $\begin{array}{c}23 \\
3\end{array}$ & 78 & 86 & 2 \\
\hline 6 & Nurjanah & 87 & 88 & $\begin{array}{c}24 \\
0\end{array}$ & 77 & 67 & 1 \\
\hline 7 & $\begin{array}{l}\text { Yolanda } \\
\text { Rindi } \\
\text { Intan } \\
\end{array}$ & 78 & 88 & $\begin{array}{c}26 \\
0\end{array}$ & 88 & 77 & 2 \\
\hline 8 & $\begin{array}{l}\text { Azelia } \\
\text { Azahra }\end{array}$ & 89 & 88 & $\begin{array}{c}25 \\
3\end{array}$ & 89 & 67 & 3 \\
\hline 9 & $\begin{array}{l}\text { Devina } \\
\text { Gayatri S }\end{array}$ & 89 & 88 & $\begin{array}{c}22 \\
4\end{array}$ & 89 & 77 & 2 \\
\hline 11 & $\begin{array}{l}\text { Nabila } \\
\text { Inas } \\
\text { Zafira }\end{array}$ & 67 & 78 & $\begin{array}{c}23 \\
2\end{array}$ & 77 & 67 & 4 \\
\hline
\end{tabular}

Nilai untuk setiap kriteria dari masing-masing alternatif sesuai tabel 4, dirubah kedalam bentuk bobot nilai sesuai dengan ketentuan pada Tabel 3 , sehingga dihasilkan Tabel 4.

Tabel 3. Penambahan Nilai

Menghitung Vektor S, menggunakan persamaan 1, seperti berikut:

$\mathrm{S} 1=$

$$
\begin{aligned}
& \left(89^{0,1538}\right)\left(90^{0,1538}\right)\left(235^{0,0769}\right)\left(78^{0,1538}\right)\left(77^{0,2307}\right)\left(4^{0,}\right. \\
& 2307=44,4958
\end{aligned}
$$

$\mathrm{S} 2=$

$\left(78^{0,1538}\right)\left(77^{0,1538}\right)\left(210^{0,0769}\right)\left(89^{0,1538}\right)\left(90^{0,2307}\right)\left(3^{0,}\right.$
$\left.{ }^{2307}\right)=41,7774$

$\mathrm{S} 3=$

$\left(78^{0,1538}\right)\left(66^{0,1538}\right)\left(240^{0,0769}\right)\left(89^{0,1538}\right)\left(88^{0,2307}\right)\left(1^{0,}\right.$

$\left.{ }^{2307}\right)=31,8234$

$\mathrm{S} 4=$

$\left(78^{0,1538}\right)\left(90^{0,1538}\right)\left(235^{0,0769}\right)\left(78^{0,1538}\right)\left(78^{0,2307}\right)\left(2^{0,}\right.$

$\left.{ }^{2307}\right)=37,2674$

$\mathrm{S} 5=$

$\left(76^{0,1538}\right)\left(77^{0,1538}\right)\left(233^{0,0769}\right)\left(78^{0,1538}\right)\left(86^{0,2307}\right)\left(2^{0,}\right.$

$\left.{ }^{2307}\right)=37,04$

S6 $=$

$\left(87^{0,1538}\right)\left(88^{0,1538}\right)\left(240^{0,0769}\right)\left(77^{0,1538}\right)\left(67^{0,2307}\right)\left(1^{0,}\right.$

$\left.{ }^{2307}\right)=31,0643$

$\mathrm{S} 7=$

$\left(78^{0,1538}\right)\left(88^{0,1538}\right)\left(260^{0,0769}\right)\left(88^{0,1538}\right)\left(77^{0,2307}\right)\left(2^{0,}\right.$
$2307)=38,0165$

$\mathrm{S} 8=$

$\left(89^{0,1538}\right)\left(88^{0,1538}\right)\left(253^{0,0769}\right)\left(89^{0,1538}\right)\left(67^{0,2307}\right)\left(3^{0,}\right.$

$\left.{ }^{2307}\right)=41,2405$

S9 =

$\left(89^{0,1538}\right)\left(88^{0,1538}\right)\left(224^{0,0769}\right)\left(89^{0,1538}\right)\left(77^{0,2307}\right)\left(2^{0,}\right.$

$2307)=38,4205$

$\mathrm{S} 10=$

$\left(67^{0,1538}\right)\left(78^{0,1538}\right)\left(232^{0,0769}\right)\left(77^{0,1538}\right)\left(67^{0,2307}\right)\left(4^{0,}\right.$

$\left.{ }^{2307}\right)=40,2303$

Menghitung preferensi (Vi) untuk perangkingan dengan menggunakan persamaan 2, didapatkan hasil seperti berikut :

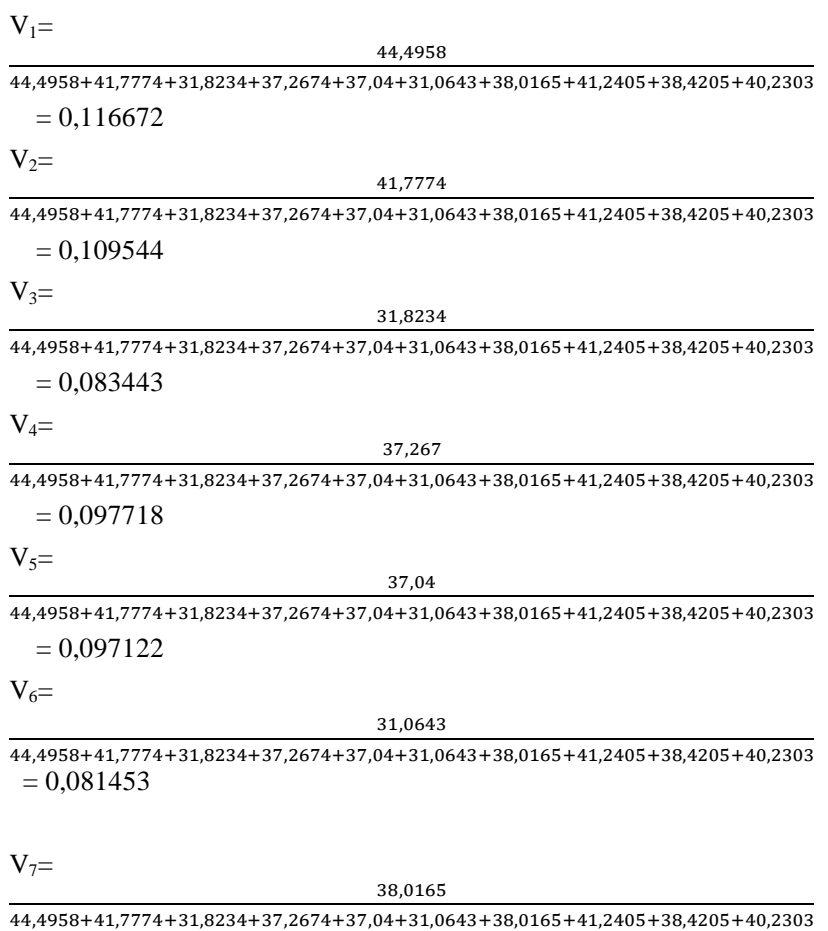


$=0,099682$

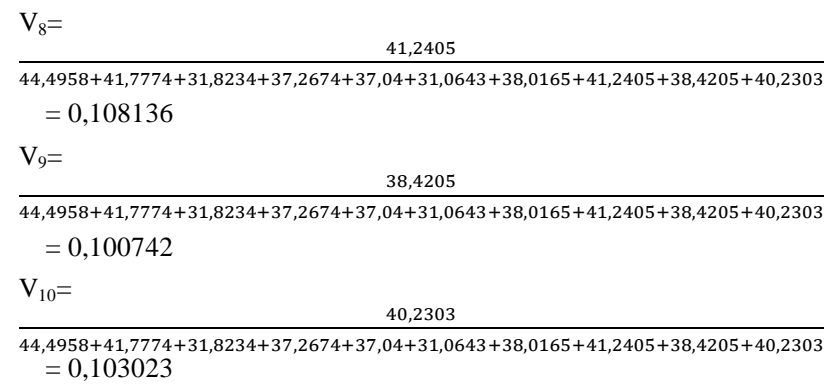

Untuk menyeleksi seluruh calon siswa maka ditetapkan nilai dibawah 0,1 maka calon siswa tersebut tidak diterima.

Tabel 4. Hasil Seleksi dengan Metode Weighted Product

\begin{tabular}{|c|c|c|c|c|}
\hline No. & ektor & Nama & Nilai & Keterangan \\
\hline 1 & V1 & $\begin{array}{l}\text { Srie } \\
\text { Fatika } \\
\text { Setiani }\end{array}$ & $\begin{array}{l}0.1166 \\
72\end{array}$ & LULUS \\
\hline 2 & V2 & $\begin{array}{l}\text { Fatwa } \\
\text { Maulida } \\
\text { Sofiani }\end{array}$ & $\begin{array}{l}0.1095 \\
44\end{array}$ & LULUS \\
\hline 3 & V8 & $\begin{array}{l}\text { Azelia } \\
\text { Azahra }\end{array}$ & $\begin{array}{l}0.1081 \\
36 \\
\end{array}$ & LULUS \\
\hline 4 & V10 & $\begin{array}{l}\text { Nabila } \\
\text { Inas } \\
\text { Zafira }\end{array}$ & $\begin{array}{l}0.1054 \\
87\end{array}$ & LULUS \\
\hline 5 & V9 & $\begin{array}{l}\text { Devina } \\
\text { Gayatri }\end{array}$ & $\begin{array}{l}0.1007 \\
42\end{array}$ & LULUS \\
\hline 6 & V7 & $\begin{array}{l}\text { Yolanda } \\
\text { Rindi } \\
\text { Intan }\end{array}$ & $\begin{array}{l}0.0996 \\
82\end{array}$ & $\begin{array}{l}\text { TIDAK } \\
\text { LULUS }\end{array}$ \\
\hline 7 & V4 & $\begin{array}{l}\text { Meita } \\
\text { Rosianti }\end{array}$ & $\begin{array}{l}0.0977 \\
18\end{array}$ & $\begin{array}{l}\text { TIDAK } \\
\text { LULUS }\end{array}$ \\
\hline 8 & V5 & $\begin{array}{l}\text { Nida } \\
\text { Luthfiyati }\end{array}$ & $\begin{array}{l}0.0971 \\
22\end{array}$ & $\begin{array}{l}\text { TIDAK } \\
\text { LULUS }\end{array}$ \\
\hline 9 & V3 & $\begin{array}{l}\text { Fikram } \\
\text { Fadilah }\end{array}$ & $\begin{array}{l}0.0834 \\
43\end{array}$ & $\begin{array}{l}\text { TIDAK } \\
\text { LULUS }\end{array}$ \\
\hline 10 & V6 & Nurjanah & $\begin{array}{l}0.0814 \\
53 \\
\end{array}$ & $\begin{array}{l}\text { TIDAK } \\
\text { LULUS }\end{array}$ \\
\hline
\end{tabular}

\section{Kesimpulan}

Beberapa hal yang dapat disimpulkan dari penelitian ini terkait dengan sistem pendukung keputusan seleksi calon siswa baru menggunakan metode Weighted Product yaitu:

1. Sistem pendukung keputusan calon seleksi siswa baru menggunakan metode Weighted Product memberikan hasil yang lebih relevan yaitu alternatif akan menjadi urutan tertinggi jika memiliki nilai yang baik pada kriteria yang memiliki kepentingan yang tertinggi.

2. Penilaian menggunakan metode Weighted Product lebih objektif terhadap siswa yang memiliki prestasi yang baik dalam bidang akademik maupun non akademik

3. Dengan adanya sistem baru, lebih memudahkan dan mempercepat para panitia untuk melakukan segala transaksi administrasi yang berkaitan dengan penerimaan calon siswa-siswi baru

\section{Daftar Pustaka}

Adam, F., Agung W., \& Isep M. (2012). Sistem Pendukung Keputusan Untuk Menyeleksi Calon Siswa Menggunakan Metode Analytic Hierarchy Process (AHP). hlm. 60-70.

Adhi, N. (2010). Rekayasa Perangkat Lunak Berorientasi Objek dengan Metode Unified Software Development Process. Yogyakarta: Andi.

Adi, P. (2012). Buku Pintar Pemrograman Web. Jakarta: Mediakita.

Asep, H., Dini D., \& Andri I. (2012). Sistem Pendukung Keputusan Penyeleksian Siswa Baru di SMA Negeri 3 Garut.Jurnal Algoritma. hlm.1-10.

Astri, H. \& Utami D. (2013). Pembangunan Sistem Pendukung Keputusan Rekrutmen Pegawai Baru di PT. ABC. Jurnal Ilmiah Komputer dan Infromatika. hlm. 43-56.

Budi, R. (2015). Belajar Otodidak MySQL. Bandung: Informatika.

Kusrini. (2007). Konsep dan Aplikasi Sistem Pendukung Keputusan. Yogyakarta: Andi.

Kusumadewi S, Hartati S, Harjoko A., \& Wardoyo R. 2006. Fuzzy Multi-Attribute Decision Making. Yogyakarta: Graha Ilmu.

Ladjamuddin, A. \& Gani, M. (2010). Pengantar

Teknologi Informasi. Tangerang: STMIK Masa Depan. 